\title{
The clinical significance of a swollen neuroma: a meaningful distinction or an incidental finding?
}

\author{
Shelby R. Svientek ${ }^{1}$, Stephen W. P. Kemp ${ }^{1,2}$, Paul S. Cederna ${ }^{1,2}$, Theodore A. Kung ${ }^{1}$ \\ ${ }^{1}$ Department of Surgery, Division of Plastic and Reconstructive Surgery, University of Michigan, Ann Arbor, MI, USA; ${ }^{2}$ Department of Biomedical \\ Engineering, University of Michigan, Ann Arbor, MI, USA \\ Correspondence to: Shelby R. Svientek. Department of Surgery, Division of Plastic and Reconstructive Surgery, University of Michigan, Ann Arbor, \\ MI, USA. Email: ssviente@med.umich.edu. \\ Comment on: Buch NS, Qerama E, Brix Finnerup N, et al. Neuromas and postamputation pain. Pain 2020;161:147-55.
}

Submitted Apr 24, 2020. Accepted for publication Sep 17, 2020.

doi: 10.21037/apm-20-1021

View this article at: http://dx.doi.org/10.21037/apm-20-1021

Symptomatic neuromas are a frequent contributor of residual limb pain, and the study by Buch et al. describes a well-designed investigation examining the relationship between swollen neuromas and postamputation pain. Chronic pain is an unfortunate consequence of amputation with approximately $65-81 \%$ of patients reporting pain that persists far beyond the expected post-surgical healing period $(1,2)$. Over 1.6 million people are living with major extremity loss in the United States (3), and up to 1.3 million of these patients suffer from chronic pain. Unfortunately, much of the existing literature on postamputation pain describes it as a unidimensional entity, failing to recognize that pain after amputation is broadly differentiated into two distinct experiences known as residual limb pain (i.e., stump pain) as well as phantom limb pain. The authors are to be commended for conducting a study that includes purposeful investigation of both of these pain subtypes and for recognizing the importance of how centrally-mediated pain is in part facilitated by peripherally-mediated pain.

In this study, the authors found no statistically significant difference in the incidence of swollen neuromas in amputation patients with pain as compared to those without pain. In addition, there was no association between stump pain or phantom pain and the presence of swollen neuromas. Furthermore, the number of swollen neuromas did not seem to be associated with stump pain or phantom pain either. These are important findings because, as the authors emphasize, a discrete identifiable bulb at the end of a transected peripheral nerve (e.g., a swollen neuroma) has been used in previous studies as a critical diagnostic criterion. Our experience affirms the authors' finding that identifiable swelling of a terminal nerve end is not in itself pathognomonic of a symptomatic (i.e., painful) neuroma. All cut peripheral nerves will attempt axonal regeneration, and without any distal targets for reinnervation, all will form neuromas. Some of these neuromas are bulbous and look swollen while others display a less impressive appearance. Some neuromas may be asymptomatic whereas others are exquisitely painful, but this is independent of the degree of swelling that is present at the distal end of the nerve.

In our practice, the diagnosis of a symptomatic neuroma is largely a clinical one and is dependent on pain solicited from the end of the nerve. A patient with a history of peripheral nerve transection with a symptomatic neuroma will demonstrate a positive Tinel's sign upon manual tapping over the distal end of the residual nerve $(4,5)$. The patient will usually experience unambiguous neuropathic pain at the site of the tapping and this helps localize the neuroma. Ultrasound imaging is not mandatory for the diagnosis of a symptomatic neuroma; however, ultrasounds can be useful in identifying smaller neuromas or confirming the presence of a neuroma in difficult cases. Injection of local anesthetic in conjunction with ultrasound imaging is highly specific for diagnosing symptomatic neuromas (6) and is a valuable way to predict that surgical intervention for a symptomatic neuroma might be effective. Other imaging modalities, including magnetic resonance imaging, computed tomography, and roentgenography, can be useful in ruling out other known causes of residual limb pain such as heterotopic ossification, osteophytes, bursitis, myositis, and infection. 


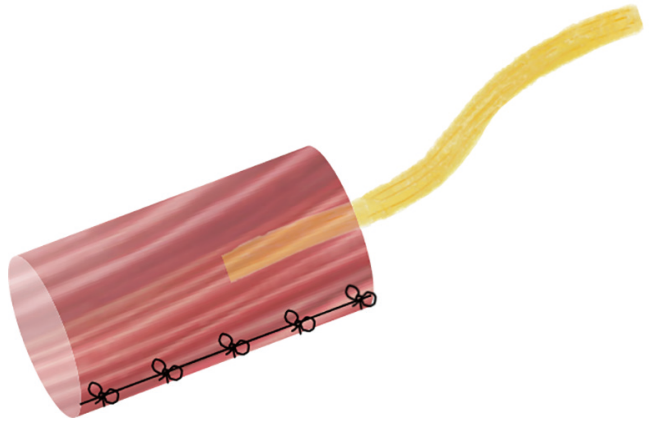

Figure 1 Illustrative Schematic of the RPNI. The muscle graft is secured to and wrapped around the free nerve ending (in yellow).

Although ultrasound imaging is a useful way to confirm the presence of a neuroma (symptomatic or not), notable limitations exit. In clinical practice, ultrasounds are highly dependent on the experience of the technician and some may not be as familiar in identifying symptomatic neuromas versus asymptomatic neuromas after amputation. Furthermore, the reliability of ultrasounds to detect soft tissue structures decreases with increasing depth, particularly in scenarios where the area of interest lies behind bone or is encased in scar, as with a tibial nerve neuroma located just posterior to the residual tibia (6). Another potential limitation in the ultrasound protocol used in this study may have been the lack of consistency in identifying all neuromas within a residual limb. In a below knee amputation, for example, the authors report scanning for neuromas along the major anatomical peripheral nerves (i.e., tibial and peroneal nerves). However, we have seen many instances where small unnamed sensory nerves contributed to a considerable amount of residual limb pain. Therefore, since ultrasound identification of neuromas was used as a means to determine study eligibility and assess study outcomes, any symptomatic neuromas that were missed may have negatively influenced results.

Despite these limitations, the authors are to be commended for their ability to recruit a considerable number of patients given the degree of rigorous testing involved in this study. Power calculations were conducted before study commencement, and the authors were able to recruit above the minimum number of patients required. However, many of the results failed to reach an effect size with statistical significance even with these statistical considerations. As many of these results were comparisons involving residual limb pain and phantom limb pain subgroups, it is possible that although the study had sufficient power to assess a relationship between neuroma swelling and post-amputation pain in general, it was underpowered to detect differences on subgroup analysis.

This study indicates that while the presence of swollen neuromas is not a driver for either residual limb pain or phantom limb pain, the transected peripheral nerves still play a critical role in contributing to postamputation pain. In recent years, clinical research in surgical techniques to treat and prevent symptomatic neuromas has placed an emphasis on leveraging regenerative strategies to minimize neuroma formation. Specifically, these techniques offer regenerating axons distal targets for reinnervation. By allowing reinnervation to occur, these approaches reduce the number of axons within a transected peripheral nerve that are available to form a symptomatic neuroma (7-10). In turn, less neuroma pain results in less residual limb pain. Furthermore, less peripheral nervous system pain is beneficial in reducing central sensitization and the likelihood of developing chronic pain (5).

The two prevailing strategies to reduce symptomatic neuromas after amputation injury are targeted muscle reinnervation (TMR) and regenerative peripheral nerve interfaces (RPNIs). Both surgical approaches were originally conceived as ways to capture efferent action potentials from transected peripheral nerves after major limb amputation to facilitate control of a prosthetic device. In addition, TMR and RPNIs were later found to also alleviate postamputation pain; although the two differ significantly in surgical technique, both alleviate neuroma pain by leveraging the biologic processes of nerve regeneration and muscle reinnervation.

RPNI surgery was developed at our institution and involves implantation of a transected nerve end into a small autologous free muscle graft (Figures 1,2). Similar to the mechanism of skin graft healing, this free muscle graft is able to revascularize and regenerate over time through nutritional support from the surrounding soft tissue and vascularity from the implanted nerve (11-13). Importantly, harvest of the free muscle graft results in complete denervation of this tissue. The implanted nerve will undergo axonal sprouting and reinnervate the free muscle graft to form new neuromuscular junctions (13-16). In doing so, the reinnervation process will reduce the number of purposeless axons contributing to neuroma formation.

RPNIs have been successfully utilized in humans as a prophylactic measure and as a treatment modality. In Woo et al. (9), sixteen patients were identified retrospectively that underwent surgery for a total of forty-six symptomatic neuromas. Following RPNI surgery, these patients on 

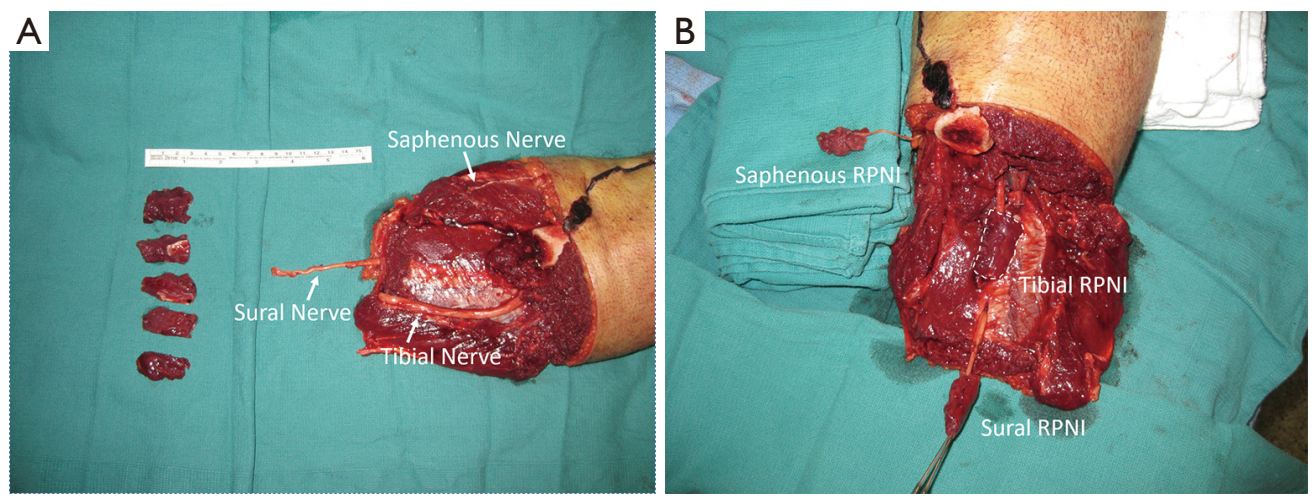

Figure 2 Regenerative peripheral nerve interface (RPNI) surgery at the time of below knee amputation. (A) Peripheral nerves are identified at the time of amputation. Multiple free muscle grafts are harvested from the amputated limb. (B) An RPNI is constructed by implanting the end of the peripheral nerve into a free muscle graft. Each muscle graft is wrapped around the nerve. The RPNIs are then positioned as proximally as possible within the residual limb before closure.

average reported a reduction in neuroma pain of $71 \%$. Remarkably, there was also a $53 \%$ reduction in phantom limb pain. In a study examining the prophylactic use of RPNIs during major limb amputation (10), forty-five patients were identified retrospectively that underwent RPNI construct implantation at time of initial extremity amputation and matched with a comparative control group. A significantly lower incidence of RPNI patients developed symptomatic neuromas compared to control patients $(0 \%$ versus $13 \%$ ), and there was also a significantly lower rate of phantom limb pain in the RPNI patients compared to control patients (51\% versus $91 \%$ ). Our clinical experience echoes the conclusion made by the Buch et al. study that postamputation pain, and specifically neuroma pain, is not related to neuroma swelling. Given the efficacy of RPNI surgery and its ability to transform the management of postamputation pain, it is in fact the lack of reinnervation after peripheral nerve transection that instigates neuroma pain and subsequently fosters phantom limb pain.

In order to further delineate the relationship between postamputation pain and the presence of swollen neuromas, the authors pursued additional objective measures of pain. Thermal and mechanical allodynia is a defining characteristic frequently observed in this population and can be a reliable measurement if assessed appropriately $(1,5,6)$. In this study, $56.6 \%$ of those with swollen neuromas were found to have quantifiable allodynia on exam as compared to only $28.6 \%$ of those without swollen neuromas. Although this finding was not statistically significant on their analysis $(\mathrm{P}=0.08)$, it may be clinically relevant, and it is possible significance could be achieved with a larger study population.
The authors additionally obtained pressure pain thresholds (PPTs) from patients identified with swollen neuromas through the use of a handheld electronic pressure algometer. We do not typically apply this technique in our practice to diagnosis neuromas, but it is a validated method that has considerable value for research purposes. In this study, the authors did not note a difference in PPT in those with $(158.8 \mathrm{kPa})$ and without $(119.0 \mathrm{kPa} ; \mathrm{P}=0.95)$ phantom pain. However, they did note a significant difference in those patients with $(134.7 \mathrm{kPa})$ and without $(144.0 \mathrm{kPa}$; $\mathrm{P}=0.004)$ residual limb pain. Despite achieving some statistical significance, these comparisons have limited clinical applicability as PPTs were only obtained from patients whose terminal nerves were identified as swollen by the authors.

Buch et al. have published an insightful study indicating that the presence of a physical swelling at the terminal nerve end identified by ultrasound imaging is not clinically meaningful in regards to the experience of neuroma pain or phantom limb pain. Their findings favor the use of clinical methods to diagnose symptomatic neuromas as opposed to relying on radiologic criteria. Their conclusions also emphasize the importance of the transected peripheral nerves in contributing to postamputation pain. Clinicians caring for amputation patients should consider exploring how methods to offer reinnervation to the transected peripheral nerves might mitigate residual limb pain and phantom limb pain after amputation.

\section{Acknowledgments}

Funding: None. 


\section{Footnote}

Provenance and Peer Review: This article was commissioned by the editorial office, Annals of Palliative Medicine. The article did not undergo external peer review.

Conflicts of Interest: All authors have completed the ICMJE uniform disclosure form (available at http://dx.doi. org/10.21037/apm-20-1021). SRS reports salary support funding from the NIH (NICHD) from the F32 NRSA Postdoctoral Research Program (5 F32 HD100286-02). PSC has a patent "Tool For Neuroma Treatment and Nerve Regeneration Procedures" (U.S. Provisional Patent Ref: 6407, HDP Ref:2115-006407-US-NPB) licensed to Inrad Corporation, Kalamazoo, Michigan. The other authors have no conflicts of interest to declare.

Ethical Statement: The authors are accountable for all aspects of the work in ensuring that questions related to the accuracy or integrity of any part of the work are appropriately investigated and resolved.

Open Access Statement: This is an Open Access article distributed in accordance with the Creative Commons Attribution-NonCommercial-NoDerivs 4.0 International License (CC BY-NC-ND 4.0), which permits the noncommercial replication and distribution of the article with the strict proviso that no changes or edits are made and the original work is properly cited (including links to both the formal publication through the relevant DOI and the license). See: https://creativecommons.org/licenses/by-nc-nd/4.0/.

\section{References}

1. Buchheit T, Van de Ven T, Hsia HL, et al. Pain Phenotypes and Associated Clinical Risk Factors Following Traumatic Amputation: Results from Veterans Integrated Pain Evaluation Research (VIPER). Pain Med 2016;17:149-61.

2. Münger M, Pinto CB, Pacheco-Barrios K, et al. Protective and Risk Factors for Phantom Limb Pain and Residual Limb Pain Severity. Pain Pract 2020;20:578-87.

3. Ziegler-Graham K, MacKenzie EJ, Ephraim PL, et al. Estimating the prevalence of limb loss in the United States: 2005 to 2050. Arch Phys Med Rehabil 2008;89:422-9.

4. Dellon AL. Tinel or not Tinel. J Hand Surg Br 1984;9:216.

5. Hsu E, Cohen SP. Postamputation pain: epidemiology, mechanisms, and treatment. J Pain Res 2013;6:121-36.

6. Arnold DMJ, Wilkens SC, Coert JH, et al. Diagnostic Criteria for Symptomatic Neuroma. Ann Plast Surg 2019;82:420-7.

7. Pet MA, Ko JH, Friedly JL, et al. Does targeted nerve implantation reduce neuroma pain in amputees?. Clin Orthop Relat Res 2014;472:2991-3001.

8. Eberlin KR, Ducic I. Surgical Algorithm for Neuroma Management: A Changing Treatment Paradigm. Plast Reconstr Surg Glob Open 2018;6:e1952.

9. Woo SL, Kung TA, Brown DL, et al. Regenerative Peripheral Nerve Interfaces for the Treatment of Postamputation Neuroma Pain: A Pilot Study. Plast Reconstr Surg Glob Open 2016;4:e1038.

10. Kubiak CA, Kemp SWP, Cederna PS, et al. Prophylactic Regenerative Peripheral Nerve Interfaces to Prevent Postamputation Pain. Plast Reconstr Surg 2019;144:421e-30e.

11. Baldwin J, Moon JD, Cederna PS, et al. Abstract 99: Early Muscle Revascularization and Regeneration at the Regenerative Peripheral Nerve Interface. Plast Reconstr Surg 2012;130:73.

12. Urbanchek MG, Wei B, Baghmanli Z, et al. Long-Term Stability of Regenerative Peripheral Nerve Interfaces (RPNI). Plast Reconstr Surg 2011;128:88-9.

13. Svientek SR, Ursu DC, Cederna PS, et al. Fabrication of the Composite Regenerative Peripheral Nerve Interface (C-RPNI) in the Adult Rat. J Vis Exp 2020;(156):10.3791/60841.

14. Kung TA, Langhals NB, Martin DC, et al. Regenerative peripheral nerve interface viability and signal transduction with an implanted electrode. Plast Reconstr Surg 2014;133:1380-94.

15. Frost CM, Ursu DC, Flattery SM, et al. Regenerative peripheral nerve interfaces for real-time, proportional control of a Neuroprosthetic hand. J Neuroeng Rehabil 2018;15:108.

16. Irwin ZT, Schroeder KE, Vu PP, et al. Chronic recording of hand prosthesis control signals via a regenerative peripheral nerve in-terface in a rhesus macaque. J Neural Eng 2016;13:046007.

Cite this article as: Svientek SR, Kemp SWP, Cederna PS, Kung TA. The clinical significance of a swollen neuroma: a meaningful distinction or an incidental finding? Ann Palliat Med 2020;9(6):4412-4415. doi: 10.21037/apm-20-1021 